\title{
Analysis of Thermal Properties on Backward Feed Multieffect Distillation Dealing with High-Salinity Wastewater
}

\author{
Jianliang Xue, ${ }^{1}$ Qinqin Cui, ${ }^{2}$ Jie Ming, ${ }^{1} \mathrm{Yu} \mathrm{Bai}^{3}{ }^{3}$ and $\mathrm{Lin} \mathrm{Li}^{1}$ \\ ${ }^{1}$ College of Chemical and Environmental Engineering, Shandong University of Science and Technology, Qingdao, \\ Shandong 266590, China \\ ${ }^{2}$ School of Architecture and Engineering, Qingdao Binhai University, Qingdao, Shandong 266555, China \\ ${ }^{3}$ Key Laboratory of Environmental Aquatic Chemistry, Research Center for Eco-Environmental Sciences, \\ Chinese Academy of Sciences, Beijing 100085, China \\ Correspondence should be addressed to Jianliang Xue; 11-1382@163.com
}

Received 7 May 2015; Accepted 25 June 2015

Academic Editor: Zhongwei Zhu

Copyright (C) 2015 Jianliang Xue et al. This is an open access article distributed under the Creative Commons Attribution License, which permits unrestricted use, distribution, and reproduction in any medium, provided the original work is properly cited.

\begin{abstract}
Theoretical investigations on thermal properties of multieffect distillation (MED) are presented to approach lower capital costs and more distillated products. A mathematical model, based on the energy and mass balance, is developed to (i) evaluate the influences of variations in key parameters (effect numbers, evaporation temperature in last effect, and feed salinity) on steam consumption, gained output ratio (GOR), and total heat transfer areas of MED and (ii) compare two operation modes (backward feed (BF) and forward feed (FF) systems). The result in the first part indicated that GOR and total heat transfer areas increased with the effect numbers. Also, higher effect numbers result in the fact that the evaporation temperature in last effect has slight influence on GOR, while it influences the total heat transfer areas remarkably. In addition, an increase of feed salinity promotes the total heat transfer areas but reduces GOR. The analyses in the second part indicate that GOR and total heat transfer areas of BF system are higher than those in FF system. One thing to be aware of is that the changes of steam consumption can be omitted, considering that it shows an opposite trend to GOR.
\end{abstract}

\section{Introduction}

Wastewater is the by-product of petrochemical enterprises, including oily wastewater, sulfur-containing wastewater, saline wastewater, and high-concentration ammonianitrogen wastewater $[1,2]$. The wastewater will be greatly harmful to the environment if they are untreated and discharged directly. Petrochemical enterprises have been plagued by saline wastewater treatment owing to its high salt and biotoxicity. The MED is one of the most successful traditional desalination technologies [3], which presents a number of advantages: low scale formation, easy operation, high performance ratio (PR), and operating with any available source of heat energy (e.g., waste heat from petrochemical enterprises and power plants) [4-6]. In each effect of MED system, pure water is produced at slightly lower pressure than the previous effect. The water evaporates at lower temperatures with the pressure decreasing; therefore, the produced vapor of the first effect evaporator serves as the heating steam for the second effect and so on [7]. An increase of effect numbers can lead to a higher PR. On the basis of energy consumption and heat transfer obtained, MED has been found to be more efficient than MSF [8].

Jernqvist et al. [9] and Ettouney [10] developed a simulation code for the MED system with shell and tube evaporators; subsequently the influences of different design parameters on PR were studied. Shakib et al. [11] developed a thermodynamic model for MED desalination with thermal vapor compression (METVC) and its main objective was optimization of METVC from economical and thermodynamic point of view. Although the general computer code and optimal model for thermoeconomic optimizations of MED desalination systems [4, 11-13] had been studied by many reports, few studies have been reported on the thermal properties of MED so far. The purpose of this work was to 
analyze the thermal properties of BF system concentrating high-salinity wastewater. Therefore, a mathematical model was developed based on mass and energy balance. In this paper, the work consisted of two parts: at first, the influences of effect numbers, evaporation temperature in last effect, and feed salinity were studied. These specifications include steam consumption, GOR, and total heat transfer areas. Furthermore, the performance comparisons between FF system and $\mathrm{BF}$ system were conducted in the second part.

\section{Mathematical Model}

The MED system usually consists of some evaporators, several flashing chambers, and a condenser. The mathematical model is developed for MED concentrating saline wastewater based on mass and energy balance. In the mathematical model, at first mass and energy balance equations have been developed for the system and then evaporator heat transfer areas balance equations are designed [14-16].

2.1. Mass Balance. In the evaporator, the mass balance can be considered as follows:

$$
M_{b, \text { in }} \times X_{b, \text { in }}=M_{b, \text { out }} \times X_{b, \text { out }} .
$$

In the flashing chamber, the mass balance can be considered as follows:

$$
M_{v}=M_{f w} \times X_{f w}
$$

where $M_{b \text {,in }}$ and $M_{b \text {,out }}$ are the mass flow rate of feed brine water and mass flow rate of condensed brine water, respectively, $t / h$.

$X_{b \text {,in }}$ and $X_{b \text {,out }}$ are the salinity concentration of feed brine water and mass flow rate of condensed brine water, respectively, \%.

2.2. Energy Balance. In the evaporator, the energy balance can be considered as follows:

$$
\begin{aligned}
& \left(M_{v, \text { in }} \times r_{\text {in }}+M_{b, \text { in }} \times C p_{b, \text { in }} \times t_{b, \text { in }}-M_{b, \text { out }} \times C p_{b, \text { out }}\right. \\
& \left.\times t_{b, \text { out }}\right) \times \eta=M_{p} \times h, \\
& C_{p} \text { : specific heat capacity, } \mathrm{J} /\left(\mathrm{kg} \cdot{ }^{\circ} \mathrm{C}\right), \\
& \eta \text { : heat utilization efficiency, } \\
& h \text { : enthalpy; } \\
& \qquad t_{v, \text { out }}=t_{b}-\mathrm{BPE}-\Delta t .
\end{aligned}
$$
follows:

The BPE is the boiling point elevation and is estimated as

$$
\begin{aligned}
\mathrm{BPE}= & X(b+C X) \times 10^{-3} \\
b= & \left(6.71+6.34 \times 10^{-2} t+9.24 \times 10^{-5} t^{2}\right) \times 10^{-3} \\
C= & \left(22.238+9.59 \times 10^{-3} t+9.24 \times 10^{-5} t^{2}\right) \\
& \times 10^{-8}
\end{aligned}
$$

The heat transfer equation is as follows:

$$
\begin{aligned}
& M_{v, \text { in }} \times r_{\text {in }}+M_{v, \text { out }} \times r_{\text {out }}=A K\left(t_{c}-t_{b}\right) \\
& K=\frac{1}{\left(1 / \alpha_{c}\right)+\left(1 / \alpha_{b}\right)+R_{w}+R_{f}},
\end{aligned}
$$

$\alpha_{c}$ : heat transfer coefficient in condensing surface, $\mathrm{W} / \mathrm{m}^{2 \circ} \mathrm{C}$;

$\alpha_{b}$ : thermal resistance of tube, $\mathrm{W} / \mathrm{m}^{2{ }^{\circ}} \mathrm{C}$;

$R_{w}$ : thermal resistance of furring, $\mathrm{W} / \mathrm{m}^{2 \circ} \mathrm{C}$;

$R_{f}$ : falling film evaporation heat transfer coefficient, $\mathrm{W} / \mathrm{m}^{2 \circ} \mathrm{C}$.

In the condenser, the calculation of energy balance is as follows:

$$
M_{v} \times r=M_{s w} \times\left(c_{p, \text { out }} \times t_{\text {out }}-c_{p, \text { in }} \times t_{b, \text { in }}\right) .
$$

The heat transfer equation is as follows:

$$
M_{v} \times r=K_{c} \times A_{c} \times \Delta t_{\mathrm{LMTD}, c} .
$$

In the flashing chamber, the mass balance can be considered as follows:

$$
\begin{aligned}
M_{v} \times r= & M_{f w, \text { in }} \times c_{p f w, \text { in }} \times t_{c, \text { in }}-M_{f w, \text { out }} \times c_{p f w, \text { out }} \\
& \times t_{c, \text { out }} \\
t_{\text {out }}= & t_{v}+\Delta t \\
\Delta t= & 0.33 \times \frac{t_{c, \text { in }}-t_{v}}{t_{v}} .
\end{aligned}
$$

2.3. Total Heat Transfer Areas Balance. In the first evaporator, the heat transfer area is calculated as follows:

$$
A_{1}=\frac{M_{b, \text { in }} \times c \times\left(t_{1}-t_{0}\right)+M_{b, \text { out }} \times r}{\eta \times\left(t_{s}-t_{v 1}-\mathrm{BPE}\right)} .
$$

In the other evaporator, the heat transfer area is calculated as follows:

$$
A_{n}=\frac{M_{b, \text { out }, n-1} \times r}{\eta \times(\Delta t-\mathrm{BPE})} .
$$

So the total heat transfer area is equal to

$$
A=A_{1}+A_{2}+\cdots+A_{n} .
$$

2.4. Calculation Parameters. Traditionally, salinity wastewater from petrochemical enterprises often contained a large percentage of organic matter (including oil type matter) and suspended matter [16]. The stability of MED process would be influenced if they were not removed. So it was firstly pretreated by biological treatment facilities, RO, and ultrafiltration (UF) to remove the organic matter and suspended matter and then entered the MED to desalinate. Therefore, the saline wastewater in this study was obtained from a typical refinery in China. In order to investigate the influences of key parameters on performance of MED, the calculation parameters of MED were shown in Table 1. 


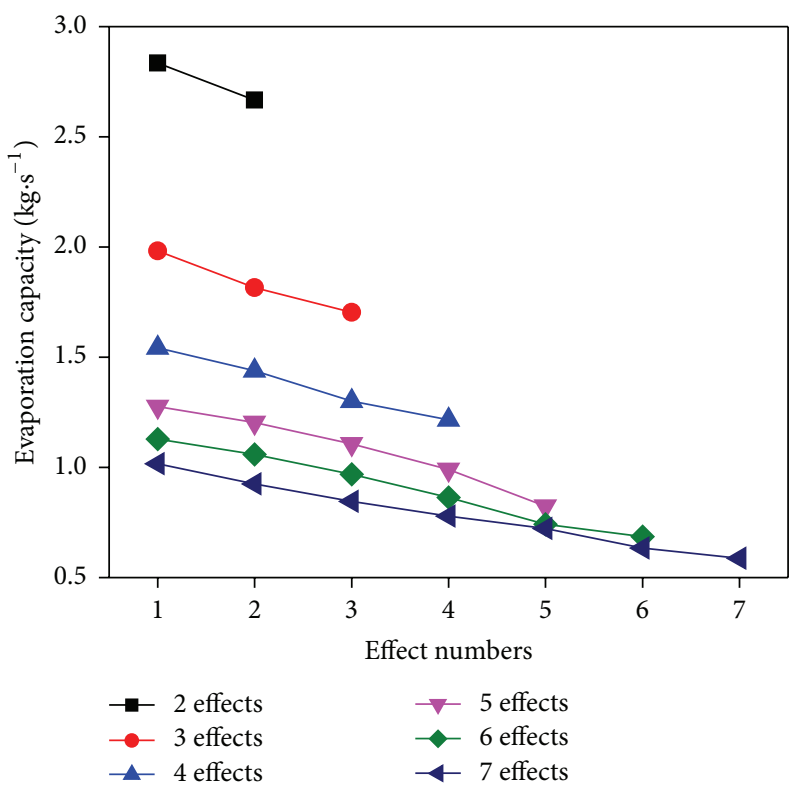

(a)

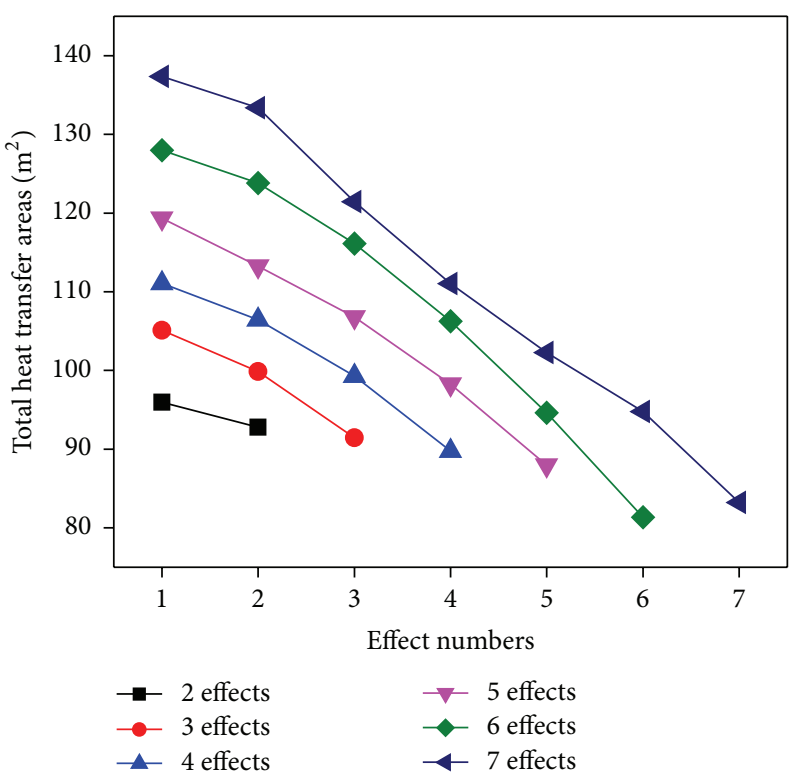

(b)

FIGURE 1: The influence of effect numbers on the evaporation capacity and heat transfer areas of each effect in MED.

TABLE 1: The calculation parameters.

\begin{tabular}{lc}
\hline Parameters & Values and unit \\
\hline Feed salinity & $0.6 \%$ \\
Discharged salinity & $3.8 \%$ \\
Evaporation temperature in first effect & $92.5^{\circ} \mathrm{C}$ \\
Cooling water temperature & $31.0^{\circ} \mathrm{C}$ \\
Distillate flow rate & $5.5 \mathrm{~m}^{3} / \mathrm{s}$ \\
Overall heat transfer coefficient of the evaporator & $2.5 \mathrm{kw} / \mathrm{m}^{2} \cdot{ }^{\circ} \mathrm{C}$ \\
Condenser effectiveness & 0.5 \\
Boiling point elevation & $1.5^{\circ} \mathrm{C}$ \\
Specific heat capacity & $4.0 \mathrm{~kJ} /\left(\mathrm{kg} \cdot{ }^{\circ} \mathrm{C}\right)$ \\
Latent heat & $2330 \mathrm{~kJ} / \mathrm{kg}$ \\
\hline
\end{tabular}

\section{Results and Discussion}

3.1. Influences of Effect Numbers on Thermal Properties of $M E D$. Figure 1(a) presented each effect evaporation capacity of different effect numbers of MED. As seen, the amount of steam generated by evaporation in each effect was less than the amount generated in the previous effect. This was due to the specific latent heat of vaporization increased with the decrease in the effect temperature. Consequently, the amount of vapor generated in an evaporator by boiling was less than the amount of condensing steam used for heating in the following evaporator. Furthermore, under the same distillated products, the higher effect numbers of MED system were, the smaller amount of each effect was. Figure 1(b) presented each effect heat transfer areas of different effect numbers of MED. Obviously, heat transfer areas of MED decreased with the increase of effect numbers in the same effect numbers of MED system, and heat transfer
TABle 2: Comparison of steam consumption, GOR, and total heat transfer areas for different effect numbers of MED.

\begin{tabular}{lccc}
\hline Effect numbers & $\begin{array}{c}\text { Steam } \\
\text { consumption, } \\
\mathrm{kg} \cdot \mathrm{s}^{-1}\end{array}$ & GOR & $\begin{array}{c}\text { Total heat transfer } \\
\text { areas, } \mathrm{m}^{2}\end{array}$ \\
\hline 2 & 2.94 & 1.87 & 188.69 \\
3 & 2.09 & 2.64 & 296.38 \\
4 & 1.61 & 3.42 & 406.56 \\
5 & 1.34 & 4.10 & 525.60 \\
6 & 1.17 & 4.70 & 650.14 \\
7 & 1.05 & 5.24 & 783.45 \\
\hline
\end{tabular}

areas of the first effect evaporator were the largest. This was because secondary steam generated each effect which reduced with effect numbers under the same distillated products, and temperature differences between each effect gradually increased, which resulted in reducing the heat transfer areas of each effect evaporator.

Table 2 showed the variation of steam consumption, GOR, and total heat transfer areas with the effect numbers at the same distillated products, respectively. It can be observed that steam consumption decreased and GOR rose with the increase of effect numbers. This was because, in the first effect, the latent heat of the feed steam was used to heat the feed water towards the saturation temperature and a smaller amount of vapor was formed. This process was repeated in subsequent effects, where the feed water was heated and an additional amount of vapor was formed. In addition, although the increment of heat transfer areas was smaller in each effect evaporator, total heat transfer areas of 


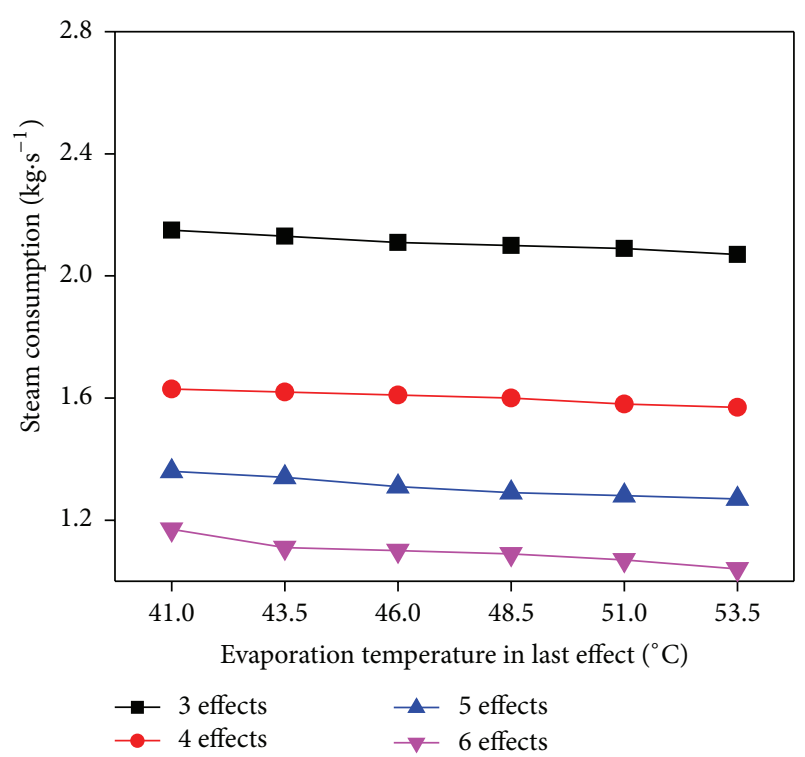

Figure 2: Variation of steam consumption with evaporation temperature in last effect.

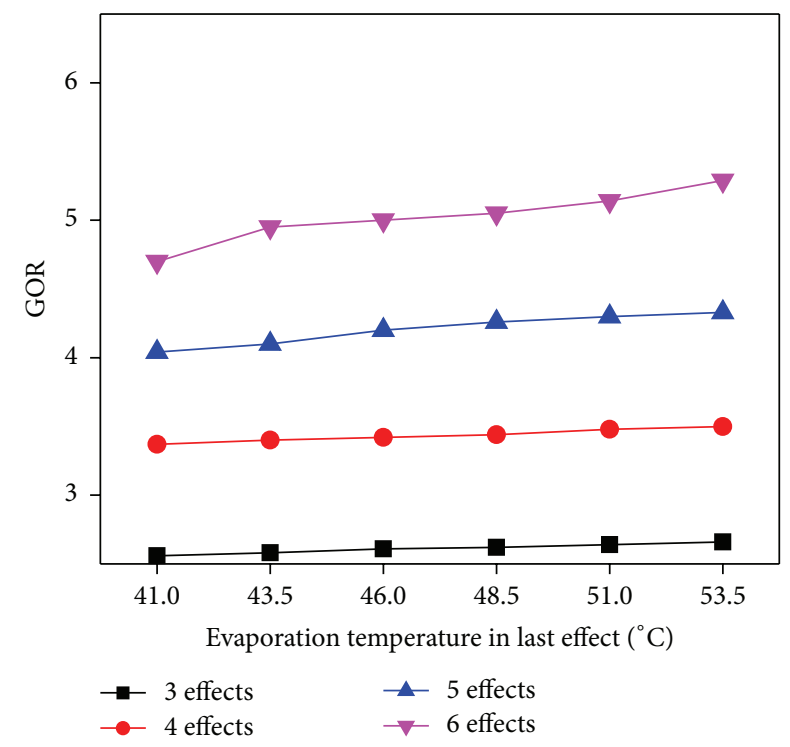

FIGURE 3: Variation of GOR with evaporation temperature in last effect.

the evaporator obviously increased with the increase of effect numbers.

\subsection{Influences of Evaporation Temperature in Last Effect on} Thermal Properties of MED. Figure 2 showed the changes in steam consumption with the increase of effect numbers under the constant distillated products. As seen, the increase in evaporation temperature in last effect reduced steam consumption due to the increase in the temperature drop per stage, which enlarged the driving force for heat transfer and reduced the steam consumption. Figure 3 presented GOR raised with the evaporation temperature in last effect. This

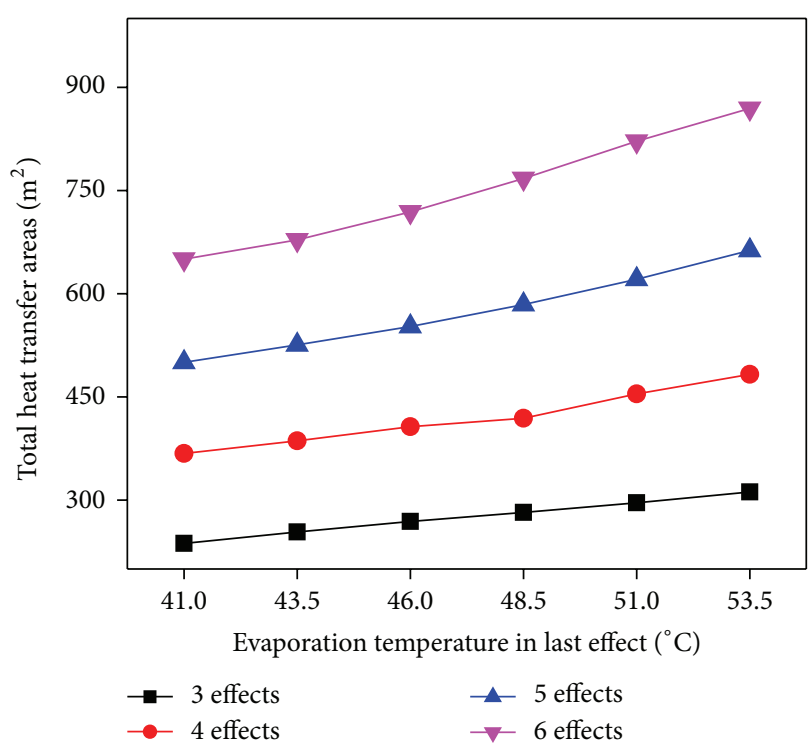

FIGURE 4: Variation of total heat transfer areas with evaporation temperature in last effect.

was mainly due to the fact that the latent heat of water vapor at high temperature was smaller [17]. Meanwhile, total evaporation capacity consisted of flashing production from brine water and fresh water besides evaporation from the transferring heat tube [18]. Thus, the amount of vapor generated in previous evaporator was more than the amount of the following evaporator. When the evaporation temperature in last effect increased, the evaporation capacity difference between adjacent effects was smaller. The amount of vapor generated from first effect increased and brine temperature from the first effect was raised, so the brine could obtain more heat. Therefore, GOR was positive correlated with evaporation temperature in last effect.

Figure 4 showed that total heat transfer areas rose with the evaporation temperature in last effect. The higher effect numbers were, the greater influence of evaporation temperature in last effect on total heat transfer areas was. The growth rate of total heat transfer areas accelerated with the increase of evaporation temperature in last effect when effect numbers were higher. For instance, when evaporation temperature in last effect increased from $41^{\circ} \mathrm{C}$ to $51^{\circ} \mathrm{C}$, total heat transfer areas increment was $26.34 \%$ and GOR increment was just $9.36 \%$ in six effects of MED. To sum up, increasing in evaporation temperature in last effect heightened slightly GOR, but bigger increment of total heat transfer areas was needed.

3.3. Influences of Feed Salinity on Thermal Properties of $M E D$. Figures 5 and 6 presented the influences of feed water salinity on steam consumption and GOR, respectively. As shown, steam consumption rose and GOR gradually decreased with the increase of the feed salinity, which meant that the treatment effect was reduced. There might be a few reasonable explanations for this phenomenon as follows. Firstly, the viscosity increased with the feed salinity, and then the diffusion coefficient and the thermal conductivity 


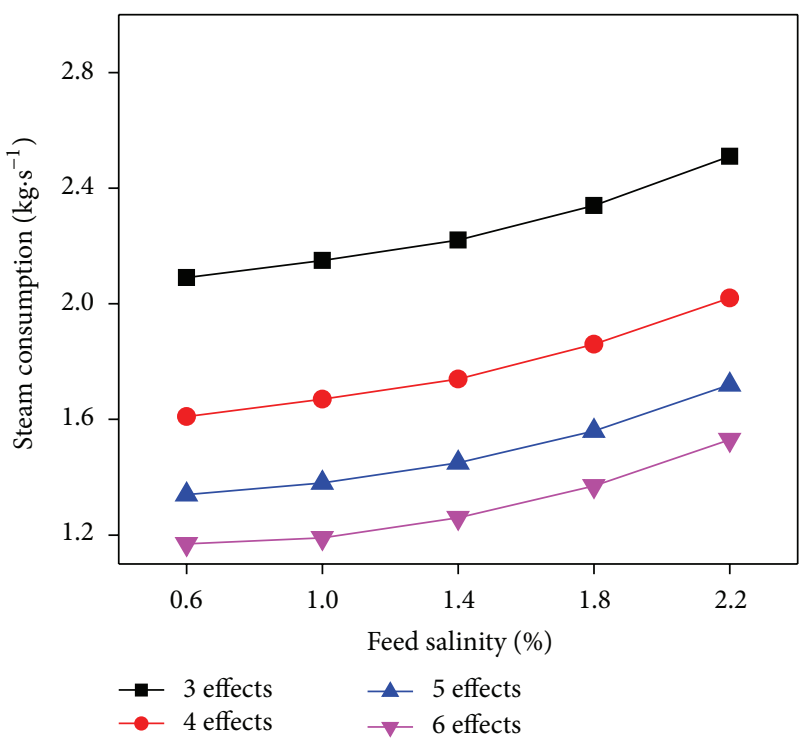

FIGURE 5: Variation of steam consumption with feed salinity.

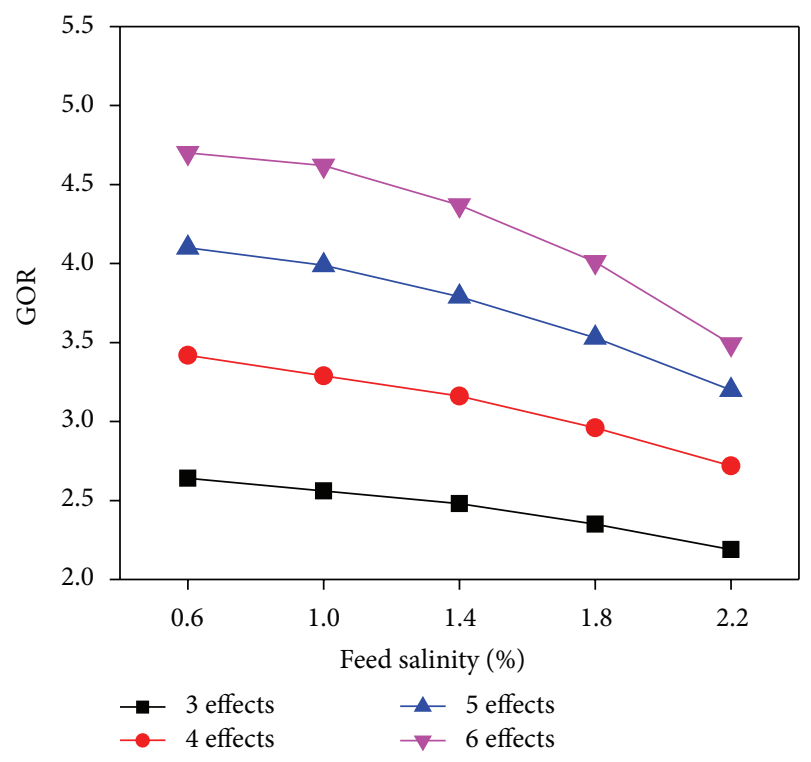

FIGURE 6: Variation of GOR with feed salinity.

in the feed solution were also reduced. At the same time, the distillated product and the secondary steam formed from each effect were reduced. In addition, the influence of the boiling point elevation (BPE) was raised with the salinity. As a result, effective heat transfer temperature difference was raised with the effect numbers and heat transfer efficiency decreased. Thereby, the thermal efficiency of the system reduced, which resulted in the increased steam consumption and the decreased GOR.

Figure 7 illustrated the influences of feed salinity on the total heat transfer areas. As seen, there was a positive correlation between evaporator total heat transfer areas and feed salinity. This was due to concentration of each effect increased with the feed salinity, so the loss of heat

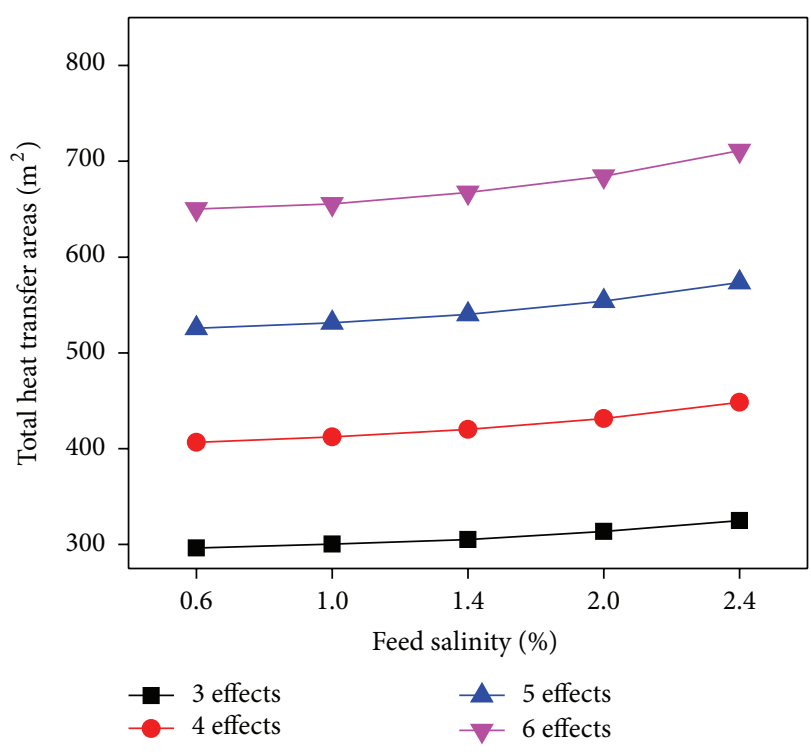

FIGURE 7: Variation of total heat transfer areas with feed salinity.

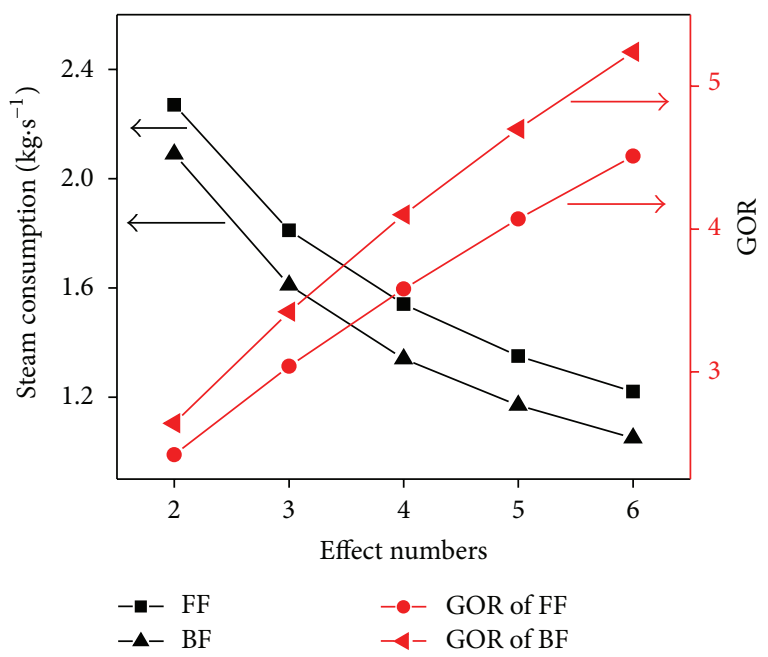

FIgURE 8: Comparison of steam consumption and GOR between FF system and BF system.

transfer temperature difference caused by BPE increased. Subsequently, a reduction of temperature difference adjacent effect and evaporation capacity of each effect resulted in an increase of total heat transfer areas.

3.4. Comparison of Performance of BF and FF. Figure 8 presented the comparison of steam consumption and GOR between FF system and BF system. As shown, these two systems had similar variations in steam consumption and GOR. With the increase of effect numbers, steam consumption decreased and GOR increased. Furthermore, BF system had lower steam consumption and higher GOR. The major cause was that BF system had a significant advantage compared with FF system. In BF system, the brine of first effect came from second effect and the brine temperature was often higher than the condenser outlet temperature. Hence, less 


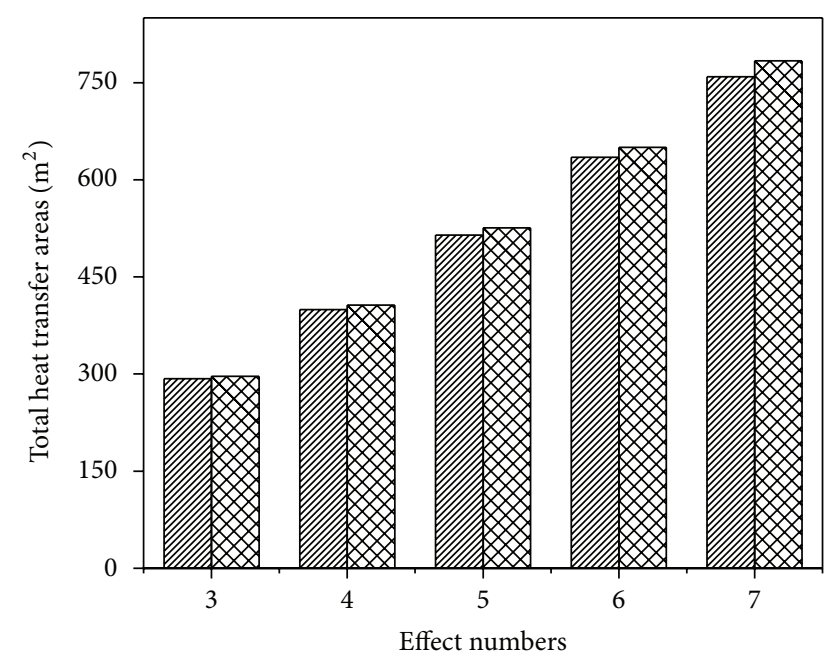

WIIIA FF BF

Figure 9: Comparison of total heat transfer areas between FF system and BF system.

feed steam heated the feed water towards the saturation temperature and more was left to heat the brine to enlarge the vapor which was generated by boiling. In invariant feed salinity and evaporation temperature in last effect, all the feed water of FF system had to be heated to the boiling temperature in the first effect before boiling commences. In other words, some of heating steam condensed did not accomplish any evaporation in the first effect. Therefore, feed steam flow rate had to be increased to maintain the constant distillated products, so BF steam had higher consumption and lower GOR.

As shown in Figure 9, total heat transfer areas of BF system were higher than FF system, and the total heat transfer areas differences between two systems increased with the effect numbers. This was because the feed water from the condenser entered the last effect; in the of BF system, the temperature of feed water was below the saturation temperature, so more evaporation areas were needed to heat the brine to the saturation temperature. However, in FF system, the feed water was supplied to the first effect of the highest temperature, and the heating brine temperature was higher than saturation temperature, so the heating brine flashed in evaporation. This was why the total heat transfer areas of FF system were lower than BF system.

\section{Conclusions}

To analyze the influences of key parameters on thermal properties of BF system concentrating high-salinity wastewater system, a mathematical model was developed based on the energy and mass balance. The results indicated that the effect numbers were very important to keep the balance between lower costs and more distillated products in the MED system. More distillated products could be produced with high effect numbers than those with low effect numbers.
Also, higher effect numbers led to higher capital costs and distillated product costs. GOR increased slightly with the evaporation temperature in last effect, but the total heat transfer areas rose greatly. The heat transfer temperature difference caused by boiling point increased with the feed salinity, which increased steam consumption and total heat transfer areas. Thereby, GOR decreased with an increase of feed salinity. Furthermore, it was observed that GOR and total heat transfer areas of BF system were higher FF system.

\section{Conflict of Interests}

The authors declare that there is no conflict of interests regarding the publication of this paper.

\section{Acknowledgments}

The authors are very grateful to the National Nature Science Foundation (Grant nos. 51408347, 51178463, 21307149, and 51474140) and Scientific Research Foundation of Shandong University of Science and Technology for Recruited Talents (Grant no. 2014RCJJ018) for financial support of this study. The authors' deepest gratitude goes to the anonymous reviewers for their careful work and thoughtful suggestions that have helped improve this paper substantially.

\section{References}

[1] D. Rajesh, C. Sunil, R. Lalita, and S. Sushila, "Impact assessment of soils treated with refinery effluent," European Journal of Soil Biology, vol. 45, no. 5-6, pp. 459-465, 2009.

[2] H. Wake, "Oil refineries: a review of their ecological impacts on the aquatic environment," Estuarine, Coastal and Shelf Science, vol. 62, no. 1-2, pp. 131-140, 2005.

[3] A. Kashi, "Investigation of energy efficiency and produced water in desalination distillation system," International Water Technology Journal, vol. 5, pp. 1-19, 2015.

[4] P. Fiorini and E. Sciubba, "Modular simulation and thermoeconomic analysis of a multi-effect distillation desalination plant," Energy, vol. 32, no. 4, pp. 459-466, 2007.

[5] H. Sayyaadi and A. Saffari, "Thermoeconomic optimization of multi effect distillation desalination systems," Applied Energy, vol. 87, no. 4, pp. 1122-1133, 2010.

[6] M. Shakouri, H. Ghadamian, and R. Sheikholeslami, "Optimal model for multi effect desalination system integrated with gas turbine," Desalination, vol. 260, no. 1-3, pp. 254-263, 2010.

[7] M. Ameri, S. S. Mohammadi, M. Hosseini, and M. Seifi, "Effect of design parameters on multi-effect desalination system specifications," Desalination, vol. 245, no. 1-3, pp. 266-283, 2009.

[8] R. Chacartegui, D. Sánchez, N. di Gregorio, F. J. JiménezEspadafor, A. Muñoz, and T. Sánchez, "Feasibility analysis of a MED desalination plant in a combined cycle based cogeneration facility," Applied Thermal Engineering, vol. 29, no. 2-3, pp. 412-417, 2009.

[9] A. Jernqvist, M. Jernqvist, and G. Aly, "Simulation of thermal desalination processes," Desalination, vol. 134, no. 1-3, pp. 187193, 2001. 
[10] H. Ettouney, "Visual basic computer package for thermal and membrane desalination processes," Desalination, vol. 165, pp. 393-408, 2004.

[11] S. E. Shakib, M. Amidpour, and C. Aghanajafi, "A new approach for process optimization of a METVC desalination system," Desalination and Water Treatment, vol. 37, no. 1-3, pp. 84-96, 2012.

[12] H. Sayyaadi, A. Saffari, and A. Mahmoodian, "Various approaches in optimization of multi effects distillation desalination systems using a hybrid meta-heuristic optimization tool," Desalination, vol. 254, no. 1-3, pp. 138-148, 2010.

[13] A. Kashi and C. Aghanajafi, "Thermo-economic analysis of a desalination device from the second law of thermodynamics' point of view and parameter investigation," International Journal of Scientific \& Engineering Research, vol. 3, pp. 1-11, 2012.

[14] C. Luo, N. Zhang, N. Lior, and H. Lin, "Proposal and analysis of a dual-purpose system integrating a chemically recuperated gas turbine cycle with thermal seawater desalination," Energy, vol. 36, no. 6, pp. 3791-3803, 2011.

[15] H. Sayyaadi and A. Saffari, "Thermo economic optimization of multi-effect distillation desalination systems," Applied Energy, vol. 87, no. 4, pp. 1122-1133, 2010.

[16] D. Zhao, J. L. Xue, S. Li, H. Sun, and Q.-D. Zhang, "Theoretical analyses of thermal and economical aspects of multi-effect distillation desalination dealing with high-salinity wastewater," Desalination, vol. 273, no. 2-3, pp. 292-298, 2011.

[17] J. L. Yan and X. F. Yu, Thermodynamic Property Tables and Diagram for Water and Steam, Higher Education Press, Beijing, China, 2004, (Chinese).

[18] W. Wei, S. Q. Shen, L. P. Yang et al., “Thermal analysis of forward feed multi-effect distillation system," Journal of Thermal Science and Technology, vol. 7, pp. 109-114, 2008 (Chinese). 

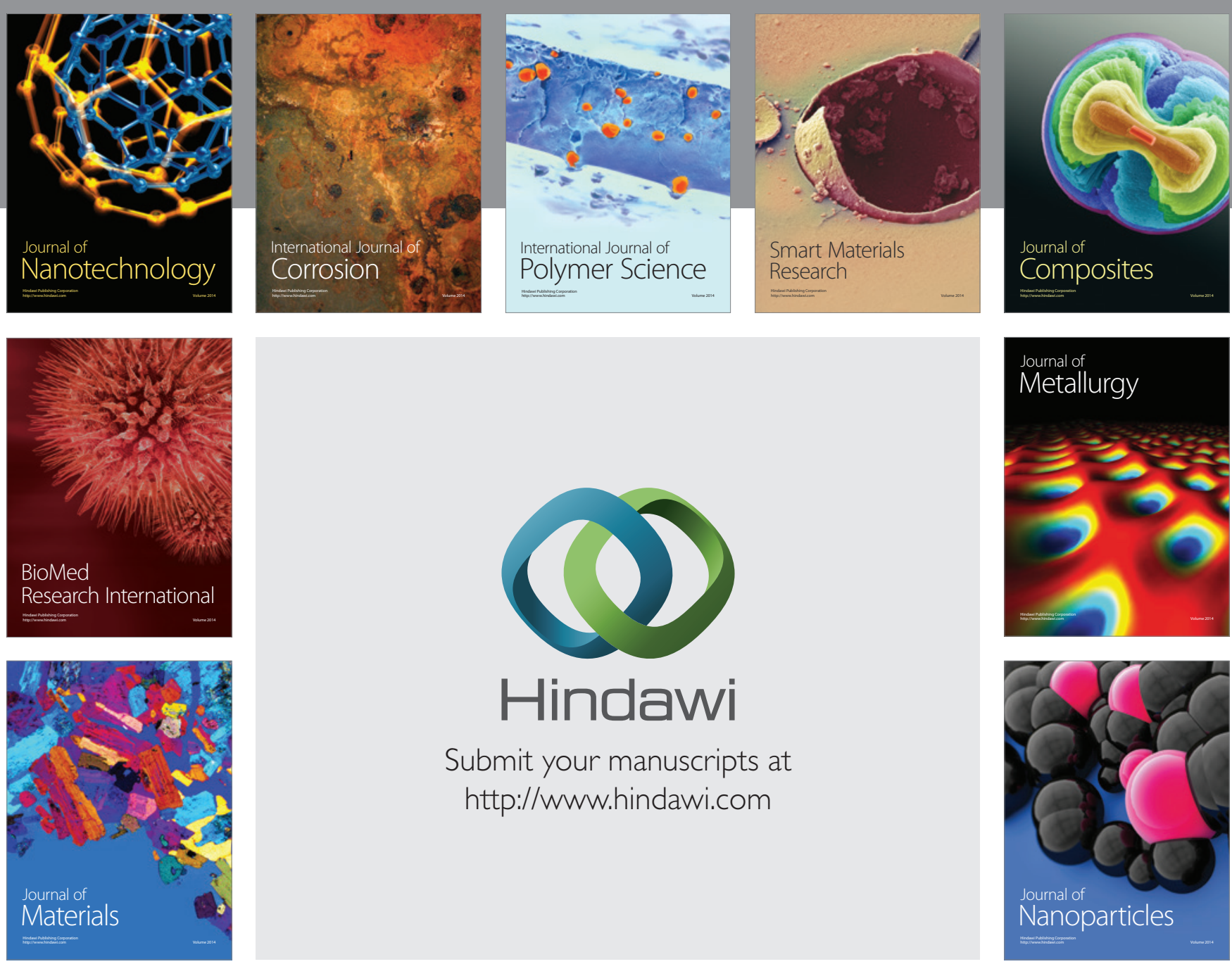

Submit your manuscripts at http://www.hindawi.com
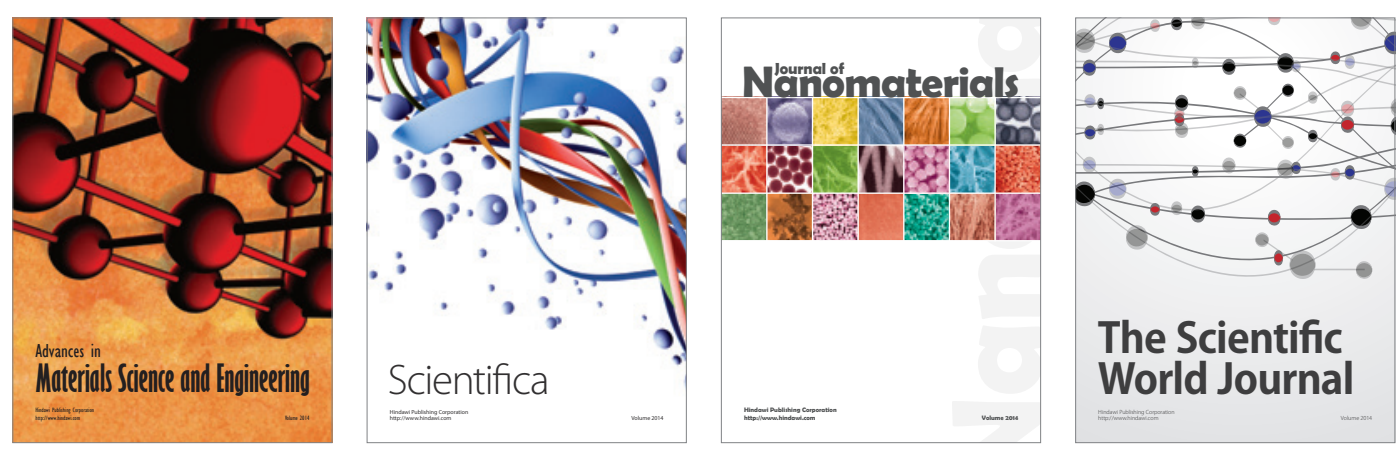

\section{The Scientific World Journal}
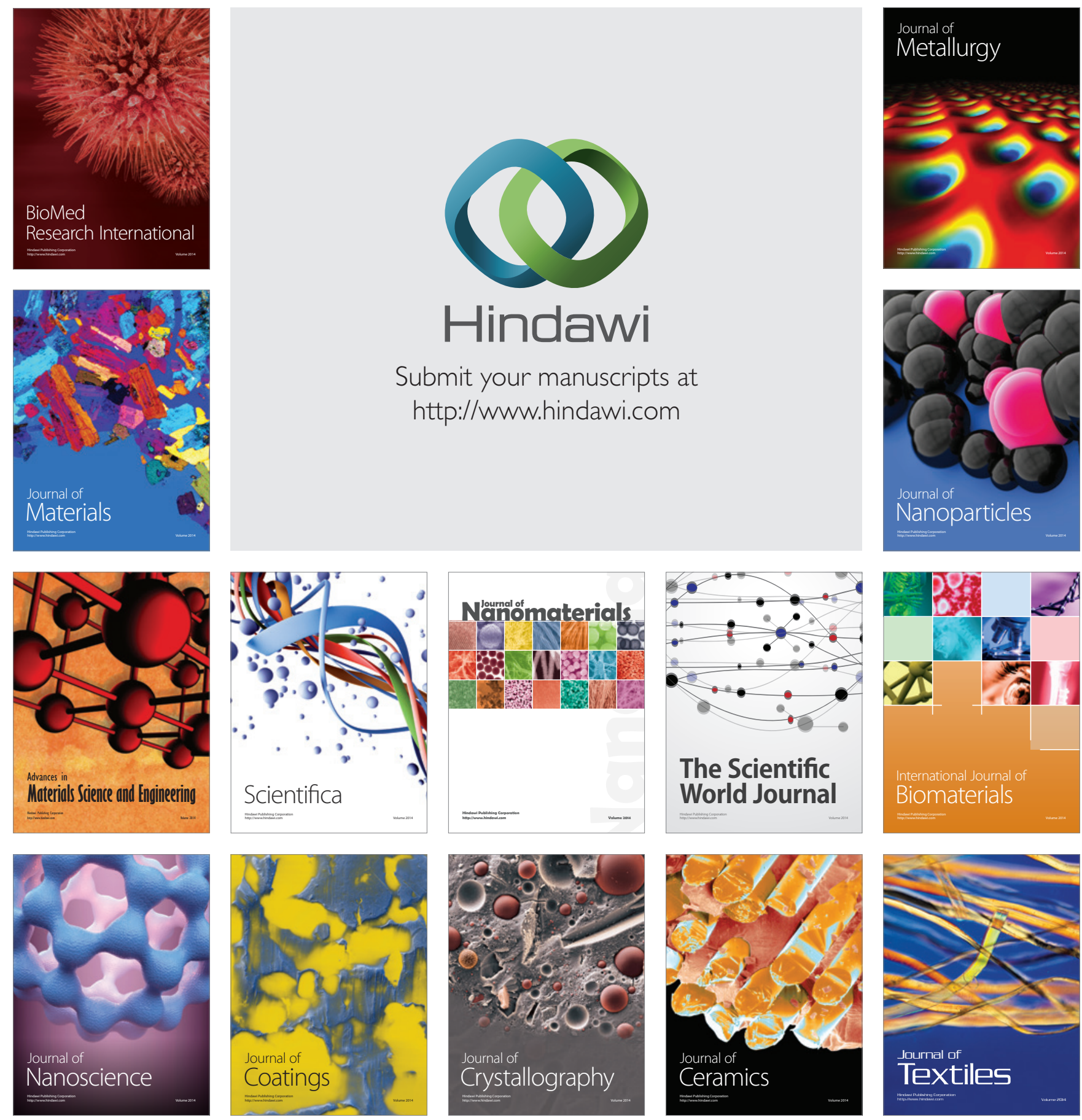